\section{Ethics and Biotechnology}

\author{
Edited by A Dyson and J Harris, \\ London, USA, Canada, Routledge, \\ 1994, 274 pages, $£ 40.66$
}

When I saw this book, I supposed that it would be concerned broadly with issues of genetic engineering in bacteria, plants, yeast, animals and humans. It is in fact a collection of essays on different aspects of genetic engineering in humans, in vitro fertilisation and experimentation on human embryos. There is little on anything other than humans, except for chapter 1 , which is about experiments on animals.

An interesting common theme is that the supposedly obvious moral distinction between somatic gene therapy and germ-line gene therapy rests on shaky foundations. Although we might reach the standard conclusion that germ-line gene therapy is unacceptable while somatic gene therapy is acceptable, several authors argue here that a closer examination of this belief should take place.

Perhaps it is more useful to distinguish between "enhancing" and "remedial" genetic engineering than between somatic and germ-line genetic engineering, though here again the distinction is not absolute.

In chapter 1, Clark makes no attempt to be dispassionate on the subject of experiments on animals.

Much of his argument against experiments on animals concerns the rejection of the humanist position, and appears to argue in favour of equal moral concern for all living things. However, he fails to rebut the standard counter-argument, which is the reductio ad absurdum that, if equal moral concern is accorded to every living thing, we should treat bacteria and viruses with equal concern to humans. It does not follow from giving preferential concern to humans that this concern is absolute.

In chapter 2, Colman adopts a more measured tone. $\mathrm{He}$ is mainly concerned with the correct balance of public and private funding of biotechnology research, and the ethical dangers that follow from private ownership or patenting of new organisms such as new crop varieties.

The first author to draw a clear distinction between remedial (therapeutic) and enhancing genetic engineering is Holm in chapter 3. However, the main problem perceived by Holm is not so much whether enhancing genetic engineering is directly unethical, but whether it could lead to "... serious and permanent injustice", because of unequal distribution of the benefit of such engineering between developed and undeveloped countries, and between rich and poor. He observes (page 52) that if there is now inadequate coverage of Third World populations by vaccination, the distribution of more sophisticated and difficult techniques such as genetic engineering would almost certainly be more inequitable.

Steinbock gives an elegant, lucid and logical account of the problems surrounding the moral and legal status of embryos and fetuses. She notes that rights can only be ascribed to beings who have interests, and that only sentient beings can have interests. The potential to become a sentient being is an inadequate qualification for rights, and it leads to an infinite regress - do sperm and ova have rights? However, as Steinbock observes, it does not follow from this argument that we should not grant human embryos (at any stage of development) a special moral status out of respect for their potential for human life. She concludes that the most important interests to be considered are therefore those of the potential parents.

In chapter 7 there is a careful examination of the ethical issues surrounding the future possibility of gene therapy for the specific purpose of eliminating infectious diseases. The author (Wood-Harper) admits that this is not yet feasible, but considers the issues that would arise if it should become feasible. She regards the genetic engineering that would be required as enhancement engineering, in the sense that the immune system would be enhanced. The discussion of the ethical questions that might arise is reasonable, but the practical and theoretical objections to the possibility of carrying this out on any scale are at present so fundamental that in my view a useful discussion of the ethics must be based on a different strategy or purpose of gene therapy. This is important, because many of the questions that arise are in fact peculiar to, or have a peculiar importance in infectious diseases - such as the size of the target population.

It is now believed that infectious diseases exert a strong and direct selection pressure on their host populations. It is abundantly clear that infectious agents can evolve thousands or, in the case of viruses, millions of times faster than their hosts, so any conceivable $\frac{1}{2}$ advantage given by gene therapy to the host would be quickly lost. Next, there is a distinct risk that enhancing some aspects of the immune system will lead to other problems such as autoimmune disease. Last, it is increasingly obvious that the resistance to infectious diseases is controlled by many genes, and $\frac{\partial}{\omega}$ the protection given by genes is rarely if $\vec{D}$ ever absolute. It will therefore be $\varrho$ extremely difficult to find a single $\%$ gene that will confer a substantially increased degree of protection. The only exception to this would be where a $\overrightarrow{\vec{\omega}}$ specific genetic defect exists: in this $\stackrel{\sigma}{\omega}$ case, it would not be gene enhancement but remedial gene therapy.

Similarly naive claims are made by H Hayry in chapter 8: "It is an un- $G$ deniable fact that genetic engineering $\omega$ can be employed to eliminate diseases $\vec{\sigma}$ ..”. In fact it is highly deniable for at 응 least three reasons. First, many com- mon diseases where there is a genetic influence are polygenic, so several genes would have to be changed in a 음 very high proportion of the population $\stackrel{\mathbb{\Phi}}{-}$ to eliminate the disease. Second, a $\vec{\bullet}$ substantial proportion of cases of $\succcurlyeq$ monogenic diseases, often about 25 $50 \%$, are caused by new mutation rather than inherited mutations. Evên combined with antenatal screening, $\overline{\text { itt }} \bar{\partial}$ is therefore doubtful whether genetic engineering would ever achieve the $\mathbb{D}$ elimination of such conditions. Lastly, engineering on a sufficient scale is at $\overrightarrow{0}$ present highly impracticable. This may of course change, but it seems doubtful whether we will ever reach the stage where a sufficient proportion of the world population can be treated to eliminate an infectious disease.

In a thoughtful, well-argued and well-written chapter (chapter 11) $\mathrm{M} \delta$ Hayry considers the categorical objections to genetic engineering. $\mathrm{He} O$ argues that objections to the possible dangers of genetic engineering are $\frac{D}{O}$ conditional on certain possibilities: that is, they are not categorical moral $N$ objections. He then goes on to argue that the claims that genetic engineer- $N$ ing is "unnatural" or "playing God" N fall into the same class of contingent $\bar{\sigma}$ rather than categorical objections.

Incidentally, why does no one claim that it is "playing God" to try and pre- $\stackrel{D}{\rightarrow}$ vent a fundamental activity such as an aspect of research?

M Hayry's is the first chapter to address head-on the ethical issues sur- $\stackrel{\odot}{\mathscr{Q}}$ rounding different forms of genetic $\stackrel{\mathbb{Q}}{\varrho}$ engineering of humans. His main con- $\bar{\sigma}$ clusion is that "the ultimate justification or rejection of biotechnology 
must be based on pragmatic considerations".

Harris (chapter 12) presents criticisms of two recent committees' reports on biotechnology and genetic engineering, the Clothier Committee and a BMA committee. He argues that many of the summary conclusions of these committees are unexamined personal prejudices that parade as moral principles. For example, why is it acceptable to try and attain certain ends such as increasing academic performance by social engineering but not by genetic engineering? $\mathrm{He}$ claims that the committees failed to examine these distinctions adequately.

Harris argues convincingly that these committees, by strenuously avoiding prescriptive behaviour, have merely followed the uninformed, unreflective prejudice of the common person, and so have misunderstood their task: "Their task, I believe, is to attempt to lead public opinion, not to follow it." He concludes that ". . . the standards of safety should not be rigged so that they effectively rule out germ-line therapy".

I found this book a stimulating and thought-provoking collection of disparate chapters, which seem to me to reflect the arbitrary and personal concerns of individuals in much the same way that scientists develop arbitrary and personal interests in certain aspects of nature. A weakness of the book is the low proportion of authors who are practising scientists. If I were to edit a book on the biology of ethics I should hope to attract several authors to write on ethics as well as biology. Having said that, I must admit that I found by far the clearest and most enjoyable chapters in this volume were written by philosophers.

C R M BANGHAM Department of Immunology, Imperial College School of Medicine, Norfolk Place, London W2 1PG

\section{Ethics in Epidemiology and Clinical Research, Annotated Readings}

Edited by Steven S Coughlin, Newton Mass, Epidemiology Resources Inc, 1995, 272 pages, US $\$ 35.00 \mathrm{pb}$.
These twenty-three articles on the ethics of epidemiological and clinical research have been selected from influential contributions to the subject written between 1963 and 1994. The material has been organised into four sections of varying lengths. The first section consists of three papers which reflect on the often notorious ethical history of epidemiological research: the opening article surveys the state of the art around the time of US Army surgeon, Walter Reed's, humanely conducted yellow fever experiments at the turn of the century. This article is followed by a study of Pasteur's work on rabies. The section is completed with Allan Brandt's article on the Tuskegee Syphilis Study, which reveals how ethically unreflective science can be permeated with highly contestable values. The Tuskegee Syphilis Study began in the 1930s and was designed to determine the natural outcome of untreated latent syphilis in black males. This study, which ran until the 1970s when it was widely condemned in the press, had built-in assumptions of racial inferiority and the crude social Darwinism which had a foothold in US science during the 1930 s. It involved a possible 100 deaths due to the withholding of treatment for experimental reasons.

In the second section five articles examine more general issues in ethics and clinical research on human subjects. The third section consists of six articles which assess ethical issues in randomised control trials. Here the familiar ethical problem is that of balancing potential harms to individual patients with the possible gains to future patients or society as a whole. The remaining nine articles in the final section focus on the evolution of ethics in epidemiology. These articles are indicative of the growing impact of bioethics on the subject. This evolutionary process can be summarised as follows: in the immediate post-war era ethical issues were rarely addressed in epidemiological literature. But in the early 1970 s scandals, such as the Tuskegee Syphilis Study, and the Jewish Chronic Disease Hospital Study (in which live cancer cells were injected into patients who had not given informed consent) fuelled concern over the potential ethical conflicts and dilemmas in epidemiology and clinical research on human subjects. By the mid-1980s discussion of both national and international guidelines was a firmly established aspect of the subject. The articles in the final section provide a comprehensive review of these ethical debates.

This is a well-balanced collection of ethical and historical topics which provides a useful guide to the development of ethical thinking in epidemiological research and the impact of bioethics on the subject.

DAVID LAMB University of Birmingham

\section{Therapy Abatement, Autonomy and Futility: Ethical Decisions at the Edge of Life}

David Lamb, Aldershot, Avebury, 1995, 146 pages, $£ 30$.

I was talking to a colleague recently about the place of euthanasia in a course on medical ethics. He replied that death had been done to death, as indeed it had in most of the recent journals coming from North America. We wondered what more there was to write about death now. I confess that I was not, for this reason, looking forward to reviewing this book - but as I settled down to read it, I found that I was really enjoying myself and resisted all attempts to distract me until I had finished.

What gripped my attention early on was the first chapter, which addresses the question of whether philosophy is relevant to medical decision-making. Lamb centres his discussion around Anne Maclean's criticism of the claim that philosophers possess special expertise when addressing moral problems in medical ethics and takes a critical look at three ways in which moral philosophy has been brought to bear on medical problems: philosophy as a means of clarification, diversionary ethics and engineering ethics. He concludes by asserting that whilst philosophers should not claim moral authority this does not mean that they have nothing of value to contribute for they can offer " . . . an ability to reason well, avoid errors in argument and recognise them in the arguments of others" (page 11). But this is only useful when philosophers also make a very real attempt to get to grips with the subject matter. "Thus, much of applied philosophy - perhaps the most interesting part - lies, not in the search for an application of the best theory, 